CLINICAL STUDY

\title{
Effects of an antiandrogenic oral contraceptive pill compared with metformin on blood coagulation tests and endothelial function in women with the polycystic ovary syndrome: influence of obesity and smoking
}

\author{
Manuel Luque-Ramírez, Covandonga Mendieta-Azcona ${ }^{1}$, José M del Rey Sánchez ${ }^{2}$, Milagro Matíes ${ }^{2}$ \\ and Héctor F Escobar-Morreale \\ Department of Endocrinology, Hospital Universitario Ramón y Cajal E Universidad de Alcalá, Carretera de Colmenar km 9'1, E-28034 Madrid, and \\ Centre de Investigación Biomédica en Red Diabetes y Enfeimedades Metabólicas Asociadas CIBERDEM, Spain, ${ }^{1}$ Department of Vascular Surgery, \\ Hospital Universitario La Paz, E-28046 Madrid, Spain and ${ }^{2}$ Department of Clinical Biochemistry, Hospital Universitario Ramón y Cajal, E-28034 \\ Madrid, Spain \\ (Correspondence should be addressed to H F Escobar-Morreale; Email: hescobarm.hrc@salud.madrid.org)
}

\begin{abstract}
Objective: To study the blood clotting tests and endothelial function of polycystic ovary syndrome (PCOS) patients and non-hyperandrogenic women, and their changes during PCOS treatment, as a function of the presence of obesity and smoking.

Design: Case-control study followed by a randomized clinical trial.

Methods: Blood clotting and endothelial function were analyzed in 40 PCOS patients and 20 nonhyperandrogenic women. Thirty-four PCOS women were randomized to an oral contraceptive containing $35 \mu \mathrm{g}$ ethinyl-estradiol plus $2 \mathrm{mg}$ cyproterone acetate (Diane ${ }^{35}$ Diario) or metformin ( $850 \mathrm{mg}$ twice daily), monitoring the changes on these parameters during 24 weeks of treatment. The influence of obesity and smoking was also analyzed.

Results: Blood clotting and endothelial function tests were similar among PCOS patients and controls with the exception of a higher platelet count in the former. Obesity increased circulating fibrinogen levels, prothrombin activity and platelet counts, and reduced prothrombin and activated partial thromboplastin times. Smoking increased fibrinogen levels, platelet counts, and prothrombin activity, and reduced prothrombin time, in relation to the larger waist circumference of smokers. Irrespective of the treatment received, PCOS patients showed a decrease in prothrombin time and an increase in prothrombin activity, with a parallel increase in homocysteine levels in metformin users. The activated partial thromboplastin time decreased markedly in the patients treated with Diane ${ }^{35}$ Diario. Finally, flow-mediated dilation improved in non-smokers irrespective of the drug received, but worsened in smokers.

Conclusions: Oral contraceptives and metformin may exert deleterious effects on blood clotting tests of PCOS women, yet the effects of metformin appear to be milder. Because smoking potentiates some of these effects and deteriorates endothelial function, smoking cessation should be promoted in PCOS patients.
\end{abstract}

European Journal of Endocrinology 160 469-480

\section{Introduction}

Cardiovascular risk markers (1-3) and early subclinical atherosclerosis $(4,5)$ cluster in women with the polycystic ovary syndrome (PCOS) as a consequence of their hyperandrogenism and insulin-resistant metabolic milieu. The latter might lead to a prothrombotic state and to endothelial dysfunction $(6,7)$, especially if amplified by the obesity $(8,9)$ frequently associated with $\operatorname{PCOS}(10,11)$.
In addition to essential lifestyle modification and weight loss strategies, the current pharmacological treatment of PCOS is based mainly on the administration of two groups of drugs: oral contraceptives and insulin sensitizers. Because oral contraceptives increase the risk for venous thrombosis in the general population (12), an effect that appears to be amplified by obesity (13) and by smoking (14), the possible adverse impact of oral contraceptives on the already unfavorable prothrombotic state of PCOS patients should be considered. 
During the past year, we have reported the results of an ample randomized controlled clinical trial (clinicaltrials.gov; NLM Identifier NCT00428311) addressing the effects of an antiandrogenic oral contraceptive pill compared with the insulin sensitizer metformin on a series of classic and non-classic cardiovascular risk factors $(3,15-18)$. In the present extended report of the aforementioned clinical trial, we show that both oral contraceptives and metformin might exert a detrimental effect on the blood coagulation tests of our young PCOS patients, whereas these drugs have no apparent major impact on their endothelial function.

\section{Subjects and methods}

\section{Subjects and experimental design}

Forty consecutive hyperandrogenic PCOS patients (age: $26 \pm 6$ (15-42) year; body mass index (BMI): $29.4 \pm 6.3$ $(18.8-47.5) \mathrm{kg} / \mathrm{m}^{2}$; number of smokers: $\left.17(43 \%)\right)$ were selected. The diagnosis of PCOS required the presence of clinical and/or biochemical hyperandrogenism together with ovulatory dysfunction, after excluding secondary etiologies (19-21). The specific methods used to establish these criteria have been reported elsewhere (22).

A control group composed by 20 non-hyperandrogenic women (age: $27 \pm 7$ (13-38) year; BMI: $28.2 \pm 6.9$ (19.8-40.8) $\mathrm{kg} / \mathrm{m}^{2}$; number of smokers: $\left.9(45 \%)\right)$ was selected as to be similar to the group of patients in terms of age, BMI, and frequency of smokers. PCOS patients and non-hyperandrogenic controls were submitted to a complete evaluation that included among other variables anthropometrical and analytical measurements and Doppler sonography-based exam of endothelial function. A detailed description of the baseline characteristics of patients and non-hyperandrogenic controls has been reported previously elsewhere (23).

None of the patients had either a personal history of hypertension, diabetes mellitus, hyperuricemia, venous thrombosis or cardiovascular events, or received treatment with oral contraceptives, antiandrogens, insulin sensitizers, vitamins or drugs that might interfere with blood pressure regulation, lipid profile, carbohydrates metabolism, blood clotting tests or endothelial function for the previous 6 months. In one patient (allocated to treatment with metformin), presenting with a history of venous thrombosis in a first-degree relative, common causes of hereditary thrombophilia were ruled out by results in assays of plasma homocysteine, antithrombin III, protein $\mathrm{C}$ and protein $\mathrm{S}$ functional activities, and of resistance to activated protein $\mathrm{C}$, within the normal range.

Thirty-four of the 40 PCOS patients agreed to participate in the randomized clinical trial (clinicaltrials.gov; NLM Identifier NCT00428311). These patients were randomly allocated to receive an oral contraceptive pill containing $35 \mu \mathrm{g}$ of ethinyl-estradiol and $2 \mathrm{mg}$ of cyproterone acetate (Diane ${ }^{35}$ Diario, $n=15$, age: $23 \pm 6$ year, BMI: $29 \pm 6 \mathrm{~kg} / \mathrm{m}^{2}$, number of smokers: $6(40 \%))$ or metformin $(n=19$, age: $25 \pm 7$ year, BMI: $31 \pm 7 \mathrm{~kg} / \mathrm{m}^{2}$, number of smokers: $8(42 \%)$ ), $850 \mathrm{mg}$ twice daily.

A detailed description of the clinical trial and baseline characteristics of the patients has been reported previously (3). The anthropometrical and analytical evaluation performed at baseline was repeated after 12 and 24 weeks of treatment, whereas plasma homocysteine concentrations and endothelial function were evaluated at baseline and after 24 weeks of treatment.

\section{Assays}

The blood samples used for the clotting tests were collected in citrate-containing tubes and were immediately mixed by gentle inversion. Fibrinogen levels were measured by the standard Clauss method (24). Blood coagulation tests were conducted using a multiparameter automatic analyzer (Dade Behring BCS, Behringwerke AG, Marburgh, Germany). The chronometric and chromogenic assays had reference ranges from 10.7 to $15.5 \mathrm{~s}$ for prothrombin time, from 60 to $130 \%$ for prothrombin activity and from 25 to $39 \mathrm{~s}$ for activated partial thromboplastin time. Platelet counts and mean platelet volume were measured by using an autoanalyser (Beckman Coulter Inc., Fullerton, CA, USA). In two patients, the initial tests showed entirely abnormal clotting profiles suggesting sample processing and/or assay errors, whereas repeated duplicate analyses conducted before treatment allocation showed results within the normal range ruling out significant coagulopathy.

Plasma homocysteine concentrations were measured by a fluorescence polarization immunoassay (IMx Homocysteine assay, Abbott Laboratories, Abbott Park, IL, USA) with a sensitivity of $0.5 \mu \mathrm{mol} / \mathrm{l}$ and total coefficients of variation below $6 \%$.

\section{Ultrasound evaluation of endothelial function}

We used the endothelial-dependent flow mediated vasodilatation and the endothelial-independent vasodilatation on the brachial artery as markers of endothelial function, using the method described by Celermajer (25) and following the guidelines of the American College of Cardiology (26). In brief, vascular reactivity was evaluated in all the women during the luteal phase of menstrual cycle by the same trained operator (C.M.A.) using a high-resolution $7.5 \mathrm{MHz}$ phased-array transducer (Imagepoint-Hx, Hewlett-Packard). Under light- and temperature-controlled conditions, and after advising the women to avoid smoking and caffeine intake for at least $4 \mathrm{~h}$ before starting the procedure, patients and controls were placed in supine with their right arms in a relaxed position. 
A longitudinal section of the right brachial artery above the elbow was obtained, and a segment of the artery yielding a clear imaging of the interface between the lumen and the anterior and posterior arterial walls was selected for all further measurements.

Scans were taken at rest, after reactive hyperemia, again at rest, and after nitroglycerin administration. After a $10 \mathrm{~min}$ rest, the resting brachial artery diameter was estimated by measuring the distance between the ' $m$ ' lines (the interface between media and adventitia) of the anterior and posterior arterial walls at the end of diastole. Reactive hyperemia was then induced by inflating a pneumatic cuff above $250 \mathrm{mmHg}$ for $3 \mathrm{~min}$ and the brachial artery diameter was estimated 30, 60, and $90 \mathrm{~s}$ after cuff deflation. Fifteen minutes were allowed for vessel recovery, and brachial artery diameter measurements were repeated $4 \mathrm{~min}$ after sublingual administration of $0.4 \mathrm{mg}$ of nitroglycerin (Trinispray, Sanofi-Aventis S.A.U., Alcobendas, Madrid, Spain). The results are presented as basal brachial artery diameter, flow-mediated vasodilatation as an index of endothelial-dependent vasodilatation (FMD, ((artery diameter after cuff deflation - basal artery diameter $) \times 100)$ /basal artery diameter)) and endothelial-independent vasodilatation (( (artery diameter after nitroglycerin - basal artery diameter $) \times 100) /$ basal artery diameter)). The coefficients of variation for brachial artery diameter before and after reactive hyperemia were 2.6 and $2.4 \%$ respectively.

\section{Statistical analysis}

Women were grouped as function of the grade of obesity (non-obese, BMI $<30 \mathrm{~kg} / \mathrm{m}^{2}$; obese, BMI $\geq 30 \mathrm{~kg} / \mathrm{m}^{2}$ ) and of smoking. The differences in continuous variables between groups were studied by one-way ANOVA or general linear models (GLM) as appropriate. Logarithmic transformation was applied to ensure normality as needed. Treatment effects on blood coagulation tests and ultrasonographic variables were analyzed by separate repeated-measures GLMs that included the arm of treatment, the presence of obesity and smoking as the between-subjects effects, and the visit of evaluation as the within-subjects effect.

The repeated-measures GLM is a statistical model where changes in a continuous dependent variable, measured more than once in the same individuals (blood coagulation tests and indexes of endothelial function in our study), are explained by a linear combination of functions of multiple independent explanatory variables (arm of treatment, obesity, and smoking in our study). In essence, the repeatedmeasures GLM is similar to a repeated-measures ANOVA, although the computational background of both tests is entirely different.

A statistically significant result from the statistic Wilks' $\lambda$ in a between-subject effect indicates differences in the dependent variable between the subjects grouped according to this effect, but without considering the within-subjects effect. A statistically significant result from the statistic Wilks' $\lambda$ in the within-subjects effects indicates that there are significant changes in the dependent variables, in all the subjects considered as a whole. And a significant statistic Wilks' $\lambda$ for the interaction among the between- and within-subjects effects indicates that the changes according to the within-subjects effects are not the same in the different groups of patients or, conversely, that the differences among the groups of patients are not the same at the different levels of the within-subjects effect.

A stepwise multiple regression analysis was used to study the changes in blood coagulation tests and in indexes of endothelial function as a function of the changes in waist circumference, free testosterone, and insulin sensitivity (with all the changes expressed as percentage of baseline values), the presence of obesity (coded 0 for non-obese patients and 1 for obese patients) and the arm of treatment (coded 0 for Diane ${ }^{35}$ Diario and 1 for metformin).

Because seven patients discontinued metformin for different reasons (3), the results obtained when considering only the patients completing the study were confirmed by intention-to-treat analysis assuming, for patients who did not complete the 24 weeks of the study, that the dependent variables had not changed at the missing visit with respect to previous visit. $P<0.05$ was considered statistically significant.

\section{Results}

\section{Case-control study}

Anthropometrical and hormonal variables PCOS patients were more hyperandrogenic and insulin resistant compared with the controls (Table 1). Compared with their non-obese counterparts, obese women had higher BMI, waist circumference, waistto-hip ratio (WHR), and free testosterone concentrations, and a reduced insulin sensitivity that was especially important in obese PCOS patients (Table 1). When smoking was introduced as an independent variable in the GLM, smokers had higher waist circumference $(88 \pm 17$ vs $82 \pm 14 \mathrm{~cm}, F=8.165$, $P=0.006)$ and WHR values $(0.83 \pm 0.10$ vs $0.78 \pm$ $0.08, \quad F=11.238, \quad P=0.002)$ compared with nonsmokers, regardless of the BMI that was similar among smokers and non-smokers $(30 \pm 7$ vs $29 \pm$ $\left.6 \mathrm{~kg} / \mathrm{m}^{2}, F=1.985, P=0.165\right)$.

Blood coagulation tests and indexes of endothelial function PCOS women showed a higher total platelet count compared with non-hyperandrogenic controls (Table 2). There were no other statistically significant differences either in fibrinogen concentrations or in any test of blood coagulation or endothelial function among PCOS women and non-hyperandrogenic controls 
Table 1 Selected anthropometrical variables and hormonal profiles of obese and non-obese polycystic ovary syndrome patients and nonhyperandrogenic control women.

\begin{tabular}{|c|c|c|c|c|c|c|c|c|c|c|}
\hline & \multicolumn{2}{|c|}{$\begin{array}{l}\text { Non-obese women } \\
\left(\mathrm{BMl}<30 \mathrm{~kg} / \mathrm{m}^{2}\right)\end{array}$} & \multicolumn{2}{|c|}{$\begin{array}{l}\text { Obese women } \\
\left(\mathrm{BMI} \geq 30 \mathrm{~kg} / \mathrm{m}^{2}\right)\end{array}$} & \multicolumn{2}{|c|}{ Effect of PCOS } & \multicolumn{2}{|c|}{ Effect of obesity } & \multicolumn{2}{|c|}{$\begin{array}{l}\text { Interaction } \\
\text { between } \\
\text { PCOS and } \\
\text { obesity }\end{array}$} \\
\hline & $\begin{array}{c}\text { Controls } \\
(n=12)\end{array}$ & $\begin{array}{l}\mathrm{PCOS} \\
(n=24)\end{array}$ & $\begin{array}{c}\text { Controls } \\
(n=8)\end{array}$ & $\begin{array}{l}\text { PCOS } \\
(n=16)\end{array}$ & $\boldsymbol{F}$ & $\boldsymbol{P}$ & $\boldsymbol{F}$ & $\boldsymbol{P}$ & $\boldsymbol{F}$ & $\boldsymbol{P}$ \\
\hline Age (year) & $26 \pm 8$ & $23 \pm 5$ & $29 \pm 6$ & $26 \pm 7$ & 2.293 & 0.136 & 2.293 & 0.136 & 0.038 & 0.846 \\
\hline Body mass index $\left(\mathrm{kg} / \mathrm{m}^{2}\right)$ & $23.3 \pm 3.2$ & $25.1 \pm 3.3$ & $35.5 \pm 3.2$ & $35.8 \pm 3.9$ & 1.073 & 0.305 & 142.889 & $<0.001$ & 0.605 & 0.440 \\
\hline Waist circumference $(\mathrm{cm})$ & $74 \pm 7$ & $76 \pm 10$ & $98 \pm 8$ & $100 \pm 13$ & 0.422 & 0.519 & 75.698 & $<0.001$ & 0.003 & 0.960 \\
\hline Waist-to-hip ratio & $0.75 \pm 0.06$ & $0.76 \pm 0.07$ & $0.83 \pm 0.08$ & $0.88 \pm 0.09$ & 2.392 & 0.128 & 22.194 & $<0.001$ & 1.249 & 0.268 \\
\hline Free testosterone (ng/dl) & $0.5 \pm 0.1$ & $1.0 \pm 0.4$ & $0.7 \pm 0.2$ & $1.6 \pm 0.7$ & 31.823 & $<0.001$ & 10.652 & 0.002 & 3.441 & 0.069 \\
\hline Insulin sensitivity index & $11.5 \pm 3.8$ & $6.3 \pm 4.0$ & $4.5 \pm 1.6$ & $2.3 \pm 1.0$ & 17.700 & $<0.001$ & 38.711 & $<0.001$ & 3.018 & 0.088 \\
\hline
\end{tabular}

Data are means \pm S.D. The differences among obese and non-obese PCOS patients and non-hyperandrogenic controls were analyzed by a two-way general linear model. To convert to SI units, multiply free testosterone by 34.67 (result in pmol//).

considered as wholes (Table 2). However, there was a statistically significant interaction between PCOS and obesity proving that non-obese PCOS women showed a reduction in prothrombin times and increased prothrombin activities that were comparable to those of obese non-hyperandrogenic women (Table 2). Compared with their non-obese counterparts, obese women had increased fibrinogen levels, prothrombin activity, and platelet counts and reduced prothrombin and activated partial thromboplastin times, although the effect of obesity on prothrombin time and activity was only present in the non-hyperandrogenic population (Table 2). Interestingly, with the exception of platelet count, all the differences between obese and non-obese women lost significance when we explored the role of the waist circumference on these effects, introducing as a covariate in GLM (data not shown).
Furthermore, the higher free testosterone levels of the obese women compared with their non-obese counterparts did not explain the effects of obesity on blood clotting tests (data not shown).

Compared with non-smokers, smokers had higher fibrinogen levels, platelet counts and prothrombin activity, and reduced prothrombin time, (Fig. 1), yet the effect on the platelet count was not observed in obese women (Fig. 1). It must be noted, however, that with the exception of the effect on the platelet count, all the undesirable effects of smoking on blood coagulation tests lost statistical significance when the waist circumference or the WHR were introduced as covariates in the GLM (data not shown).

Finally, neither PCOS nor obesity or smoking influenced any of the indexes of endothelial function (Table 2).

Table 2 Blood clotting tests, flow-mediated dilatation, and endothelial-independent vasodilation of the brachial artery in polycystic ovary syndrome patients compared with non-hyperandrogenic controls, as a function of the presence or absence of obesity.

\begin{tabular}{|c|c|c|c|c|c|c|c|c|c|c|}
\hline & \multicolumn{2}{|c|}{$\begin{array}{l}\text { Non-obese women } \\
\left(\mathrm{BMl}<30 \mathrm{~kg} / \mathrm{m}^{2}\right)\end{array}$} & \multicolumn{2}{|c|}{$\begin{array}{l}\text { Obese women } \\
\left(\mathrm{BMI} \geq 30 \mathrm{~kg} / \mathrm{m}^{2}\right)\end{array}$} & \multicolumn{2}{|c|}{$\begin{array}{l}\text { Effects of } \\
\text { PCOS }\end{array}$} & \multicolumn{2}{|c|}{$\begin{array}{l}\text { Effects of } \\
\text { obesity }\end{array}$} & \multicolumn{2}{|c|}{$\begin{array}{l}\text { Interaction } \\
\text { between } \\
\text { PCOS and } \\
\text { obesity }\end{array}$} \\
\hline & $\begin{array}{l}\text { Controls } \\
(n=12)\end{array}$ & $\begin{array}{l}\text { PCOS } \\
(n=24)\end{array}$ & $\begin{array}{l}\text { Controls } \\
(n=8)\end{array}$ & $\begin{array}{l}\text { PCOS } \\
(n=16)\end{array}$ & $\boldsymbol{F}$ & $\boldsymbol{P}$ & $\boldsymbol{F}$ & $\boldsymbol{P}$ & $\boldsymbol{F}$ & $\boldsymbol{P}$ \\
\hline Fibrinogen (mg/dl) & $254 \pm 35$ & $280 \pm 43$ & $337 \pm 70$ & $367 \pm 77$ & 3.172 & 0.080 & 29.339 & $<0.001$ & 0.020 & 0.888 \\
\hline Prothrombin time (s) & $13 \pm 2$ & $12 \pm 1$ & $12 \pm 1$ & $12 \pm 1$ & 3.433 & 0.069 & 8.301 & 0.006 & 5.705 & 0.020 \\
\hline Prothrombin activity (\%) & $89 \pm 19$ & $100 \pm 9$ & $106 \pm 12$ & $101 \pm 15$ & 0.738 & 0.394 & 5.787 & 0.019 & 4.582 & 0.037 \\
\hline $\begin{array}{l}\text { Activated partial thrombo- } \\
\text { plastin time (s) }\end{array}$ & $33 \pm 3$ & $32 \pm 4$ & $30 \pm 3$ & $30 \pm 2$ & 0.006 & 0.937 & 7.157 & 0.010 & 0.822 & 0.369 \\
\hline Mean platelet volume (fl) & $9.3 \pm 0.9$ & $9.1 \pm 0.8$ & $9.2 \pm 1.1$ & $8.8 \pm 1.1$ & 1.565 & 0.216 & 0.986 & 0.325 & 0.218 & 0.642 \\
\hline Platelet count $\left(\times 10^{3} / \mu \mathrm{l}\right)$ & $223 \pm 40$ & $251 \pm 44$ & $267 \pm 60$ & $297 \pm 64$ & 4.169 & 0.046 & 9.804 & 0.003 & 0.002 & 0.961 \\
\hline $\begin{array}{l}\text { Baseline brachial artery } \\
\text { diameter }(\mathrm{cm})\end{array}$ & $0.36 \pm 0.04$ & $0.35 \pm 0.04$ & $0.39 \pm 0.04$ & $0.34 \pm 0.06$ & 3.549 & 0.065 & 0.820 & 0.369 & 2.392 & 0.128 \\
\hline Flow-mediated dilatation (\%) & $5.6 \pm 9.3$ & $7.1 \pm 10.7$ & $5.3 \pm 5.4$ & $10.3 \pm 9.6$ & 1.480 & 0.229 & 0.305 & 0.583 & 0.419 & 0.520 \\
\hline $\begin{array}{l}\text { Endothelial-independent } \\
\text { vasodilatation (\%) }\end{array}$ & $22.4 \pm 9.8$ & $23.5 \pm 10.4$ & $15.3 \pm 10.2$ & $25.0 \pm 7.4$ & 1.620 & 0.208 & 0.122 & 0.728 & 2.081 & 0.155 \\
\hline
\end{tabular}

Data are means \pm s.D. The differences among non-obese and obese PCOS women and non-hyperandrogenic controls were analyzed by two-way general linear model. To convert to SI units, multiply fibrinogen by 0.0294 (result in $\mu \mathrm{mol} / \mathrm{l}$ ). 

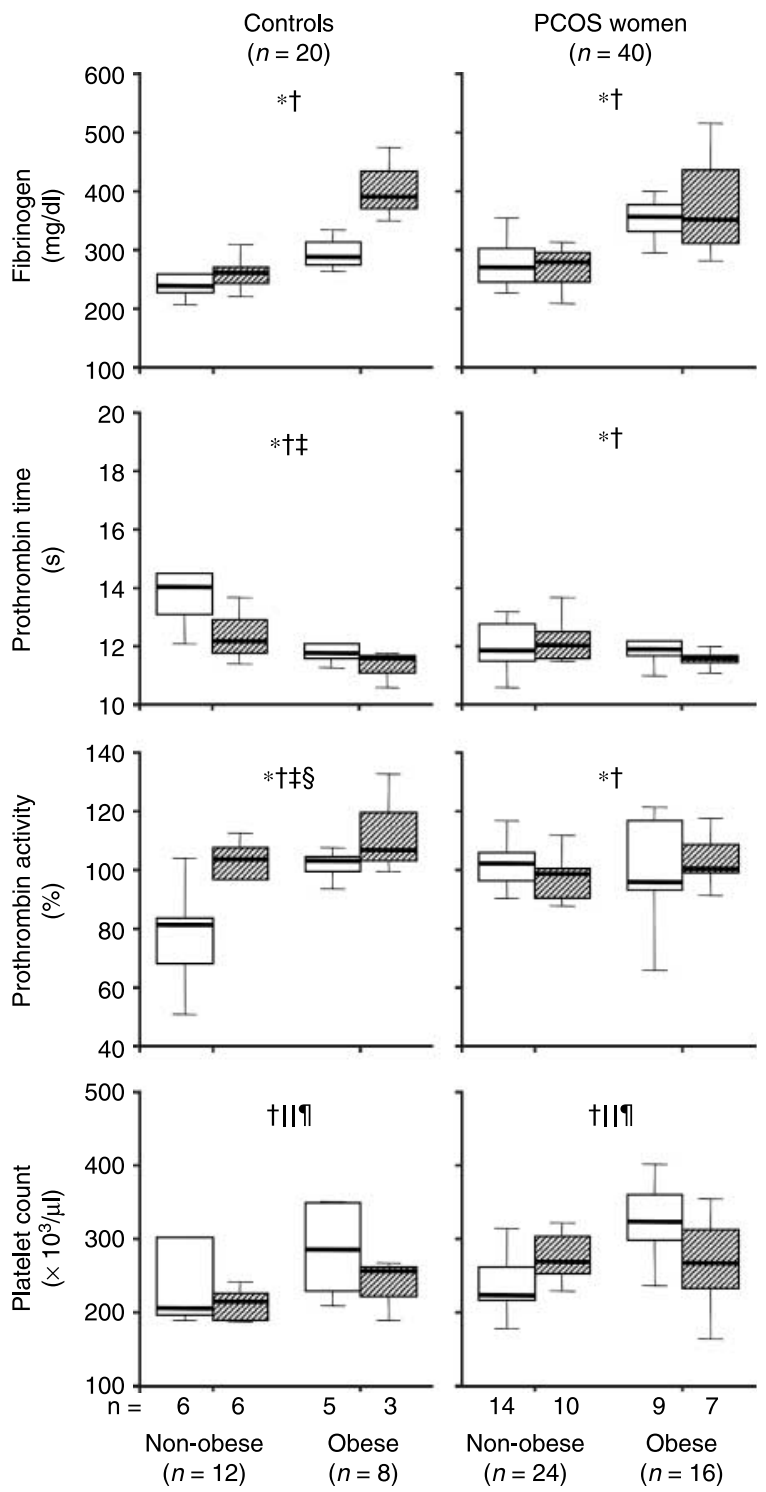

Figure 1 Influence of PCOS, smoking, and obesity on plasma fibrinogen concentrations, prothrombin time and activity, and platelet counts. Data were submitted to a GLM that included PCOS, smoking, and obesity as independent variables. The white boxes represent non-smokers and the patterned boxes represent smokers. The box-plot includes the median (horizontal line) and the interquartile range (box), and the whiskers indicate the minimum and maximum data values, unless outliers are present in which case the whiskers extend to a maximum of 1.5 times the interquartile range. The figures below the $X$-axis indicate the number of subjects in each subgroup. ${ }^{*} P<0.05$ for the differences between women smokers and non-smokers. $\dagger P<0.05$ for the differences between obese and non-obese women. $\ddagger P<0.05$ for the interaction between PCOS status and the presence of obesity. $\S P<0.05$ for the interaction between PCOS status and smoking. $\| P<0.05$ for the interaction between smoking and the presence of obesity. $\Phi P<0.05$ for the differences between PCOS patients and nonhyperandrogenic women.

\section{Randomized clinical trial}

The baseline characteristics of the patients allocated initially to Diane ${ }^{35}$ Diario or metformin, and those of the women on metformin who completed the study, are summarized in Table 3. There were no differences at baseline between the women allocated to Diane ${ }^{35}$ Diario, the women allocated to metformin who started the randomized trial, and the women allocated to metformin who completed the study (Table 3). There was no difference in the frequencies of smokers either among the women allocated to receive metformin who started the trial or those who completed it ( 42 vs $42 \%, \chi^{2}=$ $0.001, P=0.981$ ) or among the women who started the trial in the Diane ${ }^{35}$ Diario arm of treatment and those who completed the treatment with metformin (40 vs $42 \%, \chi^{2}=0.008, P=0.999$ ) and PCOS patients did not change their smoking habits throughout the study.

Fibrinogen Plasma fibrinogen concentrations changed differently in the PCOS patients treated with Diane ${ }^{35-}$ Diario; these levels decreased in obese patients reaching normal values, but increased in the non-obese ones (Fig. 2) reaching fibrinogen levels that were higher than those of the non-hyperandrogenic controls (Fig. 2). On the contrary, metformin did not induce any change in fibrinogen levels (Fig. 2).

These changes in plasma fibrinogen concentrations were associated only with the changes in waist circumference (stepwise multiple regression model: $R^{2}=0.181, \beta=0.461, P=0.015$; by intention-to-treat analysis: $\left.R^{2}=0.172, \beta=0.443, P=0.009\right)$. The changes in plasma fibrinogen with treatment throughout the study were similar in smokers and in nonsmokers (data not shown).

Prothrombin time and activity When considered as a whole, PCOS patients suffered a decrease in prothrombin time and an increase in prothrombin activity during the clinical trial (Fig. 2), which was caused by the changes observed in the non-obese patients irrespective of the treatment received, and in the obese women treated with metformin (Fig. 2). On the contrary, no changes were observed in obese PCOS patients on Diane ${ }^{35}$ Diario (Fig. 2).

Compared with non-hyperandrogenic controls, the prothrombin time was reduced and the prothrombin activity was increased throughout the study in the nonobese subgroup of patients irrespective of the treatment applied (Fig. 2). In obese patients, however, these variables were comparable with the controls at baseline, but became abnormal during treatment only in the subgroup of obese women allocated to metformin (Fig. 2). Of note, only one obese patient allocated to metformin presented with mildly decreased prothrombin time and mildly increased prothrombin activity at the end of the study, whereas these 
Table 3 Baseline characteristics of polycystic ovary syndrome patients randomly allocated to receive Diane ${ }^{35}$ Diario or metformin.

\begin{tabular}{|c|c|c|c|c|c|}
\hline & $\begin{array}{c}\text { Diane } e^{35} \text { Diario } \\
\quad(n=15)\end{array}$ & $\begin{array}{l}\text { Metformin (inten- } \\
\text { tion-to-treat } \\
\text { analysis) }(n=19)\end{array}$ & $\begin{array}{l}\text { Metformin (patients } \\
\text { completing the } \\
\text { study) }(n=12)\end{array}$ & $\boldsymbol{F}$ & $\boldsymbol{P}$ \\
\hline Age (year) & $23 \pm 6$ & $25 \pm 7$ & $25 \pm 7$ & 0.351 & 0.706 \\
\hline Body mass index $\left(\mathrm{kg} / \mathrm{m}^{2}\right)$ & $29.2 \pm 5.7$ & $30.5 \pm 6.9$ & $28.4 \pm 6.0$ & 0.441 & 0.646 \\
\hline Waist circumference $(\mathrm{cm})$ & $83 \pm 12$ & $89 \pm 18$ & $85 \pm 16$ & 0.543 & 0.585 \\
\hline Waist-to-hip ratio & $0.79 \pm 0.06$ & $0.82 \pm 0.11$ & $0.80 \pm 0.09$ & 0.646 & 0.529 \\
\hline Free testosterone $(\mathrm{ng} / \mathrm{dl})$ & $1.1 \pm 0.4$ & $1.3 \pm 0.6$ & $1.2 \pm 0.6$ & 0.781 & 0.464 \\
\hline Insulin sensitivity index & $4.4 \pm 3.5$ & $3.8 \pm 2.4$ & $4.1 \pm 2.8$ & 0.179 & 0.837 \\
\hline Fibrinogen (mg/dl) & $311 \pm 81$ & $326 \pm 75$ & $299 \pm 41$ & 0.578 & 0.566 \\
\hline Prothrombin time (s) & $12 \pm 5$ & $12 \pm 1$ & $12 \pm 0.8$ & 0.072 & 0.931 \\
\hline Prothrombin activity (\%) & $103 \pm 7$ & $99 \pm 14$ & $101 \pm 11$ & 0.409 & 0.667 \\
\hline Activated partial thromboplastin time (s) & $30 \pm 2$ & $32 \pm 4$ & $33 \pm 5$ & 2.220 & 0.121 \\
\hline Mean platelet volume (fl) & $9.0 \pm 1.0$ & $9.0 \pm 1.0$ & $8.8 \pm 0.9$ & 0.157 & 0.856 \\
\hline Platelet count $\left(\times 10^{3} / \mu \mathrm{l}\right)$ & $273 \pm 58$ & $268 \pm 56$ & $251 \pm 46$ & 0.601 & 0.553 \\
\hline Baseline brachial artery diameter $(\mathrm{cm})$ & $0.36 \pm 0.04$ & $0.35 \pm 0.05$ & $0.36 \pm 0.05$ & 0.558 & 0.576 \\
\hline Flow-mediated dilatation (\%) & $7.5 \pm 9.4$ & $7.2 \pm 10.0$ & $4.5 \pm 10.7$ & 0.341 & 0.713 \\
\hline Endothelial-independent vasodilatation (\%) & $22.5 \pm 8.1$ & $25.7 \pm 10.9$ & $25.3 \pm 12.3$ & 0.422 & 0.658 \\
\hline
\end{tabular}

Data are means \pm s.D. The differences among groups of treatment were analyzed by one-way ANOVA. The $F$ and $P$ values showed no differences among any of the groups in the variables presented here. To convert to SI units, multiply fibrinogen by 0.0294 (result in $\mu$ mol/l) and free testosterone by 34.67 (result in $\mathrm{pmol} / \mathrm{l})$.

parameters remained within the normal range in all the other patients throughout the study.

The stepwise multiple regression analysis did not show any statistically significant association between the changes observed in prothrombin time and activity with the changes in waist circumference, free testosterone, and insulin sensitivity (data not shown). Smoking showed no statistically significant effect on prothrombin time or activity (data not shown).

Because the effect of metformin on prothrombin time and activity might be mediated by a decrease in the intestinal absorption of vitamin $B_{12}$, with a subsequent increase in homocysteine levels which in turn increases tissue factor and activates the extrinsic coagulation pathway (27), we measured homocysteine levels at baseline and at the end of the study. Plasma homocysteine concentrations increased in the PCOS patients treated with metformin, irrespective of smoking and obesity, and in the smokers allocated to Diane ${ }^{35}$ Diario, whereas these levels actually decreased with the oral contraceptive in non-smokers (Fig. 3). However, the influence of smoking on circulating homocysteine did not reach statistical significance when waist circumference was introduced as a covariate in the GLM.

Activated partial thromboplastin time The activated partial thromboplastin time decreased throughout the study in the patients treated with Diane ${ }^{35}$ Diario, irrespective of the presence or absence of obesity and smoking (Fig. 2). As a consequence of this change, at the end of the study, the activated partial thromboplastin time of the patients treated with Diane ${ }^{35}$ Diario was shorter than that of the patients treated with metformin and than that of the non-hyperandrogenic controls, which were similar (Fig. 2). Of note, one obese patient and one non-obese woman on Diane ${ }^{35}$ Diario presented with mildly decreased activated partial thromboplastin times at the end of the study, whereas this variable remained within the normal range in all the other patients throughout the study.

In the stepwise multiple regression analysis, the changes observed in activated partial thromboplastin time throughout the trial were associated only with the arm of treatment in favor of the administration of metformin (stepwise multiple regression model: $R^{2}=$ $0.329, \beta=-0.596, P=0.001$; by intention-to-treat analysis: $\left.R^{2}=0.403, \beta=-0.649, p<0.001\right)$, whereas no other association was observed either in the obese or non-obese women.

Platelet markers The mean platelet volume increased slightly during the trial in PCOS patients irrespective of the treatment applied, obesity and smoking, yet the increase only reached statistical significance in the intention-to-treat analysis, and the mean platelet volume attained was not different when compared with non-hyperandrogenic controls (Fig. 4). These changes in platelet volume were associated only with the change in abdominal circumference (stepwise multiple regression model: $R^{2}=0.122, \beta=-0.394$, $P=0.042$; by intention-to-treat analysis: $R^{2}=0.142$, $\beta=-0.410, P=0.016$ ).

The platelet count showed a small decrease in the obese women treated with Diane ${ }^{35}$ Diario that reached statistical significance only in the intention-to-treat analysis (Fig. 3), whereas no changes were observed in non-obese patients on Diane ${ }^{35}$ Diario or in women treated with metformin (Fig. 4).

Also according to the intention-to-treat analysis, smoking resulted in an increase in the platelet count that was independent of the arm of treatment and of obesity (Wilks' $\lambda$ : 0.756, F: 3.875, $P=0.035$ ), yielding 

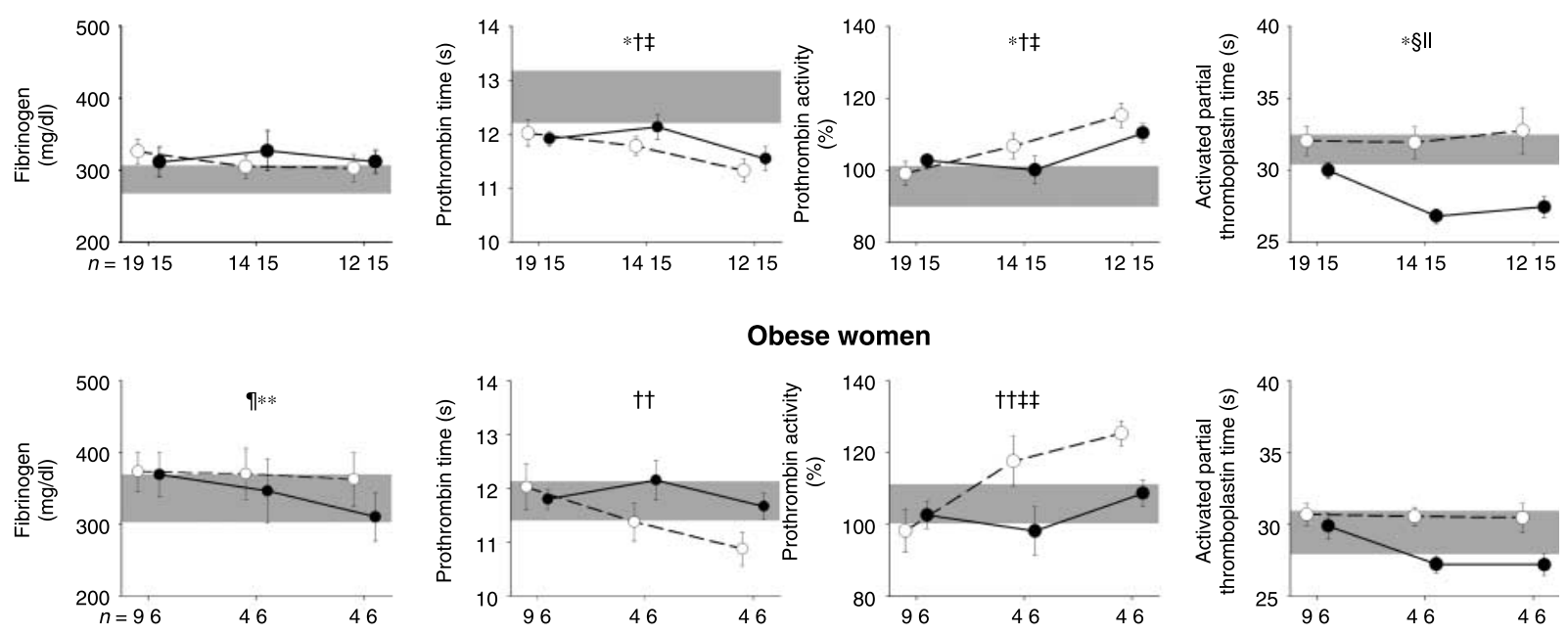

Obese women

Non-obese women
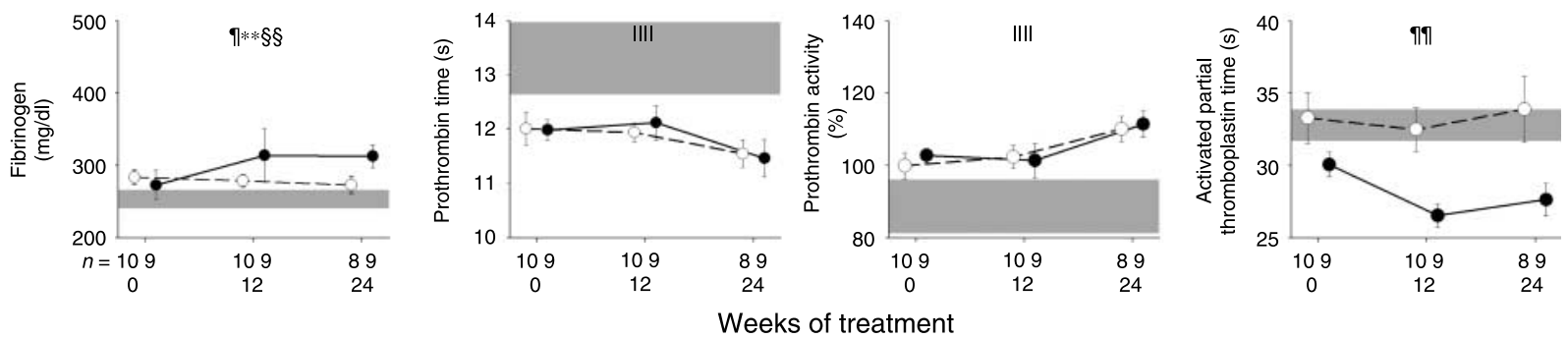

Figure 2 Changes in the blood clotting tests of PCOS patients submitted to treatment with Diane ${ }^{35}$ Diario or metformin for 24 weeks, as a function of obesity. Black circles represent the data from the patients allocated to Diane ${ }^{35}$ Diario, whereas white circles represent the data from the patients allocated to metformin. The small figures under the $X$-axis indicate the number of patients at each visit. Data are means \pm S.E.M., and were submitted to a repeated-measures general lineal model introducing the arm of treatment and the presence or absence of obesity and smoking as between-subjects effects, and the visit of evaluation (baseline, 12 and 24 weeks) as the within-subjects effect. The shaded areas represent the $95 \%$ confidence intervals of the control group of non-hyperandrogenic women. The results were evaluated according to the analysis of the patients who completed the study and also according to intention-to-treat analysis. ${ }^{*} P<0.05$ for the changes observed throughout the trial compared with baseline values considering all patients as a whole irrespective of the arm of treatment (in the analysis of the patients who completed the study and by intention-to-treat analysis). $\dagger P<0.05$ for the differences observed in the changes of each variable depending on the arm of treatment (in the analysis of the patients who completed the study). $\ddagger P<0.05$ for the differences between the values of PCOS patients at the end of the study, irrespective of the arm of treatment, and those of the control group of non-hyperandrogenic women (in the analysis of the patients who completed the study and by intention-to-treat analysis). $\S P<0.05$ for the differences observed in the changes of each variable depending on the arm of treatment (by analysis of the patients who completed the study and by intention-to-treat analysis). $\| P<0.05$ only for PCOS women on Diane ${ }^{35}$ Diario compared with PCOS women on metformin and with the control group of non-hyperandrogenic women (in the analysis of the patients who completed the study and by intention-to-treat analysis). $\Psi P<0.05$ for the changes observed throughout the trial compared with baseline values among obese and non-obese women, irrespective of the arm of treatment (only by intention-to-treat analysis). ${ }^{* \star} P<0.05$ for the differences observed in the changes of each variable with respect to baseline depending on the arm of treatment and of obesity (in the analysis of the patients who completed the study and by intention-to-treat analysis). †† $P<0.05$ for the differences observed in the changes of each variable with respect to baseline depending on the arm of treatment and of obesity (in the analysis of the patients who completed the study). $¥ \ddagger P<0.05$ only for obese PCOS women on metformin compared with the control group of obese non-hyperandrogenic women (in the analysis of the patients who completed the study). $\S \S P<0.05$ only for non-obese PCOS women on Diane ${ }^{35}$ Diario at the end of the study compared with the non-obese control subgroup (in the analysis of the patients who completed the study and by intention-to-treat analysis). \|\| $\mid P<0.05$ for non-obese PCOS patients at the end of the study compared with the non-obese control subgroup, irrespective of the arm of treatment (in the analysis of the patients who completed the study and by intention-to-treat analysis). $9 \uparrow P<0.05$ only for non-obese PCOS women on Diane ${ }^{35}$ Diario compared with non-obese PCOS women on metformin at the end of the study and with the non-obese control subgroup (in the analysis of the patients who completed the study and by intention-to-treat analysis).

values that were nevertheless not different compared with those of the controls (Fig. 4). These small changes did not show any significant association in the multiple regression analysis (data not shown).
Indexes of endothelial function None of the indexes of endothelial function changed during the study as a function of the drug used for treatment and of the presence or absence of obesity (Fig. 4). FMD improved with both 


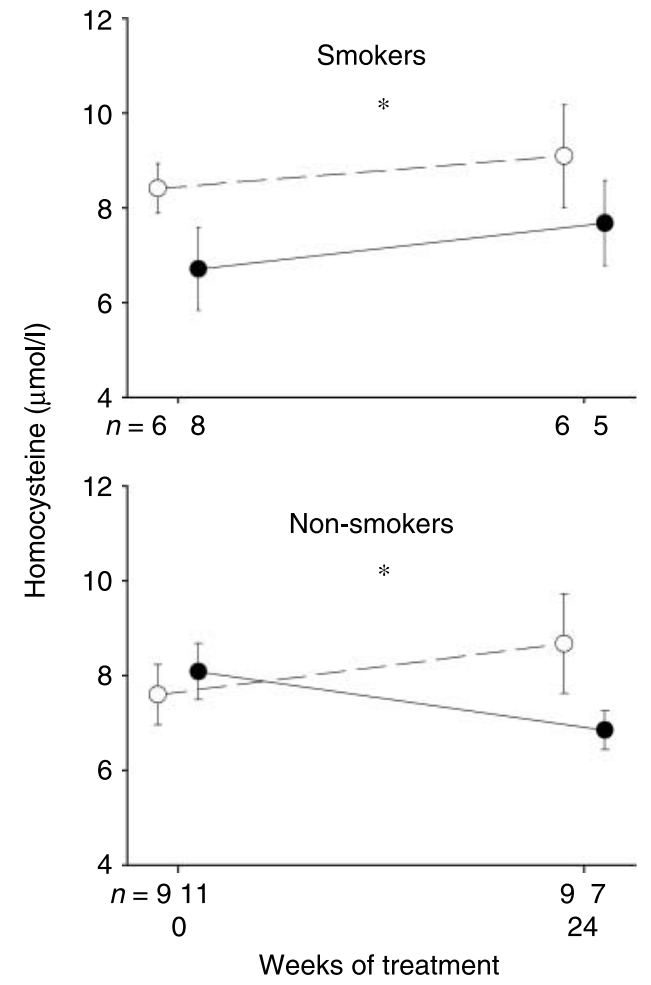

Figure 3 Changes in homocysteine levels of PCOS patients submitted to treatment with Diane ${ }^{35}$ Diario or metformin for 24 weeks as a function of smoking. Black circles represent the data from PCOS women on Diane ${ }^{35}$ Diario, whereas white circles represent the data from the PCOS women on metformin. The upper panel represents the data of smokers and the lower panel represents the data of non-smokers PCOS women. The small figures under the $X$-axis indicate the number of patients at each visit. Data are means \pm s.E.M., and were submitted to a repeatedmeasures general lineal model introducing the arm of treatment, the presence or absence of obesity and smoking as between-subjects effects, and the visit of evaluation (baseline and 24 weeks) as the within-subjects effect. The results were evaluated according to the analysis of patients who completed the study and to the intentionto-treat analysis. ${ }^{*} P<0.05$ for the differences observed in the changes of each variable with respect to baseline depending on the arm of treatment and of smoking (in the analysis of the patients who completed the study and by intention-to-treat analysis).

drugs in non-smokers and worsened in smokers, irrespective of obesity (Fig. 5). On the contrary, neither the arm of treatment nor obesity or smoking influenced endothelium-independent vasodilatation (Fig. 4).

Finally, the change in FMD was associated only with the changes observed in waist circumference (stepwise multiple regression model: $R^{2}=0.118, \beta=-0.390$, $P=0.044$; by intention-to-treat analysis: $R^{2}=0.100$, $\beta=-0.358, P=0.041$ ).

\section{Discussion}

Our present results indicate that obesity and abdominal adiposity influence the abnormalities in blood coagulation found in PCOS patients, as has been also demonstrated for many other cardiovascular risk factors frequently associated with this prevalent disorder $(10,23)$.

The young PCOS patients studied here presented a procoagulant profile consisting of increased plasma fibrinogen levels and platelet counts, and decreased prothrombin times. Non-obese PCOS patients had prothrombin times and activities that were comparable to those of obese non-hyperandrogenic women, and clearly abnormal when compared with the non-obese controls. These findings suggest that PCOS is not only associated with abnormalities in fibrinolysis (6), but also with thrombophilia in conceptual agreement with the effect of insulin resistance on coagulation previously reported in the general population (8).

Furthermore, our results indicate that smoking amplifies the blood coagulation abnormalities found here, and that this deleterious effect appears to be mediated, at least partly, by the abdominal adiposity of smokers. In this regard, abdominal adiposity is not only an intrinsic characteristic of PCOS patients (10) but also very common in smokers in studies conducted in the general population (28-30). The fact that the effect of smoking on the blood coagulation abnormalities found in our series of young women was no longer statistically significant when correcting for the influence of abdominal adiposity strongly suggests that the synergistic effect of PCOS and smoking on abdominal adiposity may worsen the prothrombotic profile of these women $(31,32)$.

To our best knowledge, our present study is the first evaluating the differential effects that oral contraceptive pills and metformin might exert on the blood clotting tests of PCOS women, considering also the impact of obesity and smoking.

In conceptual agreement with the increase in the risk of venous thromboembolism reported with the use of oral contraceptives in the general population - which derives from the facilitation of the liver synthesis of procoagulant factors and the induction of resistance to activated protein C (33) - Diane ${ }^{35}$ Diario also exerted a detrimental effect on the clotting tests evaluating extrinsic and intrinsic coagulation pathways in our series of young PCOS patients. However, although Diane ${ }^{35}$ Diario is still considered a safe drug for the treatment of PCOS (34) and it has been suggested that the risk of thrombotic events in women taking oral contraceptives containing ethinyl-estradiol plus cyproterone acetate (the components of Diane ${ }^{35}$ Diario) does not appear to be higher than that observed with other third generation oral contraceptive pills, this issue is still a matter of debate (35). Therefore, although the overall effect of oral contraceptives on the classic and nonclassic cardiovascular risk markers associated with PCOS is beneficial in our experience $(3,15-18)$, it must be noted that others have reported an undesirable impact of contraceptive pills on the cardiovascular risk profile of these women (36-38). 
Obese and non-obese women as a whole
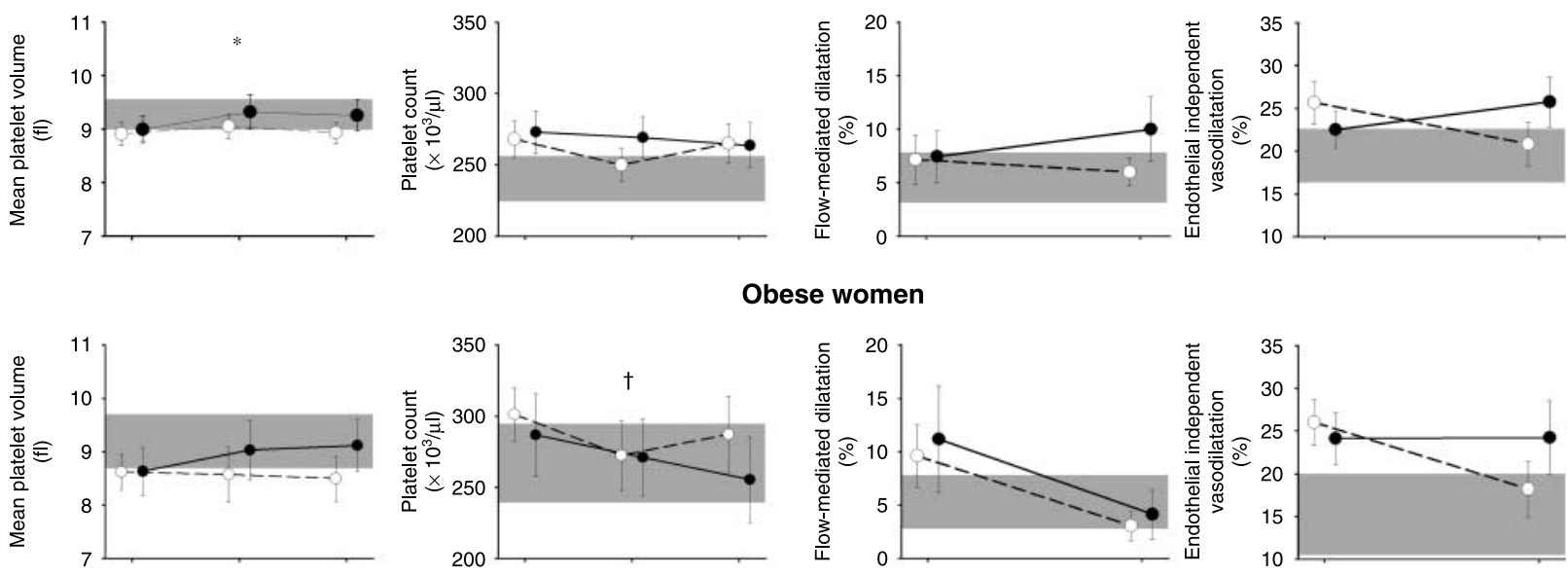

Non-obese women
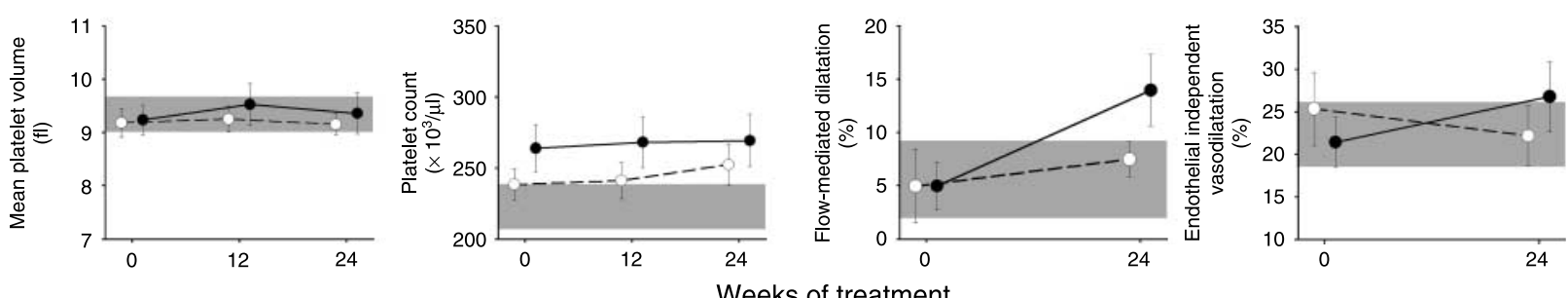

Figure 4 Changes in platelet markers and endothelial function of PCOS patients submitted to treatment with Diane ${ }^{35}$ Diario or metformin for 24 weeks, as a function of obesity. Black circles represent the data from the patients allocated to Diane ${ }^{35}$ Diario, whereas white circles represent the data from the patients allocated to metformin. The small figures under the $X$-axis indicate the number of patients at each visit. Data are means \pm S.E.M., and were submitted to a repeated-measures general lineal model introducing the arm of treatment and the presence or absence of obesity and smoking as between-subjects effects, and the visit of evaluation (baseline, 12 and 24 weeks) as the within-subjects effect. The shaded areas represent the $95 \%$ confidence intervals of the control group of non-hyperandrogenic women. The results were evaluated according to the analysis of patients who completed the study and to the intention-to-treat analysis. ${ }^{*} P<0.05$ compared with baseline values in the whole group of patients, irrespective of the arm of treatment (by intention-to-treat analysis). $\dagger P<0.05$ for the differences observed in the changes of each variable with respect to baseline depending on the arm of treatment and of obesity (by intention-to-treat analysis).

Of interest, some of the effects of Diane ${ }^{35}$ Diario on blood coagulation parameters are modulated by obesity: while this contraceptive pill increases fibrinogen levels in non-obese PCOS patients, the opposite effect was observed in the obese subgroup of patients treated with this drug, because fibrinogen concentrations decreased in parallel with the reduction in the waist circumference observed in these women (18). Together with our previous finding of an increase in serum adiponectin levels only in the obese women treated with Diane ${ }^{35-}$ Diario, the present finding of a reduction of fibrinogen levels in these women may suggest that, in sharp contrast to what has been published (38), oral contraceptives could have beneficial effects in obese PCOS patients that are not present in the non-obese subgroup.

But more surprising is the finding of a worsening in blood clotting tests, consisting of a decrease in prothrombin time and an increase in prothrombin activity, in the PCOS patients allocated to treatment with metformin in our study. Despite the beneficial impact of metformin on some aspects of the cardiovascular risk profile of PCOS women $(15,16)$, metformin might reduce vitamin $\mathrm{B}_{12}$ absorption thereby increasing homocysteine levels (39). Considering that homocysteine increases the rate of synthesis of tissue factor, which in turn activates the extrinsic coagulation pathway (27), the finding of an increase in plasma homocysteine concentrations during treatment with metformin suggests that this mechanism may contribute to the parallel changes in prothrombin time and activity observed in our patients. In conceptual agreement, an increase in circulating homocystein levels during metformin administration to PCOS patients has been previously reported $(40,41)$, although this finding is not universal (42).

The fact that the undesirable effects of metformin on prothrombin time and activity were especially important in the subgroup of obese PCOS patients may be explained by the fact that obesity may be associated per se with a decrease in vitamin $B_{12}$ levels (43), and 


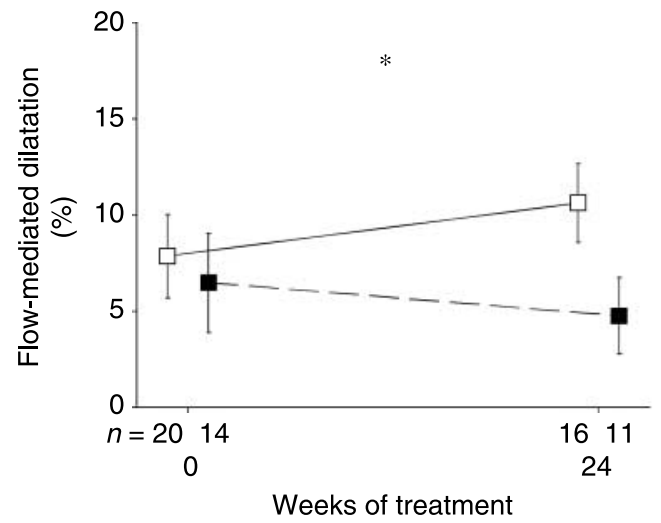

Figure 5 Changes in blood flow-mediated dilatation of the whole of PCOS patients submitted to treatment with Diane ${ }^{35}$ Diario or with metformin for 24 weeks, as a function of smoking. Black squares represent the data from the smokers irrespective of the arm of treatment, whereas white squares represent the data from the nonsmokers patients irrespective of the arm of treatment. The small figures under the $X$-axis indicate the number of patients at each visit. Data are means \pm S.E.M., and were submitted to a repeatedmeasures general lineal model introducing the arm of treatment, the presence or absence of obesity, and smoking as between-subjects effects, and the visit of evaluation (baseline and 24 weeks) as the within-subjects effect. The results were evaluated according to the analysis of patients who completed the study and to the intentionto-treat analysis. ${ }^{*} P<0.05$ for the effect of smoking on FMD throughout the study considering patients as a whole and irrespective of the arm of treatment and of obesity (in the analysis of the patients who completed the study and by intention-to-treat analysis).

this relative deficiency might be amplified by metformin administration leading to the increase in homocysteine concentrations mentioned above. However, because we did not find any effect of obesity on baseline homocysteine levels, this hypothesis remains merely speculative. Nevertheless, considering that increased homocysteine concentrations appear to mediate the effects of metformin on prothrombin time and activity, this undesirable effect could be prevented by the concurrent administration of calcium, vitamin B or folic acid supplements $(41,44)$, whereas the undesirable effects of oral contraceptives on coagulation cannot be avoided. Furthermore, despite the small magnitude of the changes in blood clotting tests observed here as a result of PCOS treatment that, with a few individual exceptions, occurred within the normal range, it must be highlighted that even mild reductions of activated partial thromboplastin time increased the risk for thrombotic events in large population studies (45).

In our series of young PCOS patients, there were no obvious abnormalities in the indexes of endothelial function evaluated, despite the fact that the patients were insulin resistant when compared with nonhyperandrogenic controls matched for age and BMI. Although insulin resistance is related with the appearance of endothelial dysfunction in subjects with type 2 diabetes, it has been postulated that variations in the mechanism of insulin resistance in PCOS patients may affect endothelial function differently (46). The insulin resistance of PCOS patients has been proposed to involve a post-receptor defect in the phosphatidylinositol 3-kinase insulin-signaling pathway (47) that may reduce the vasodilatatory action of insulin (48), thereby favoring the vasoconstrictory action through the MAP kinase pathway (49). Yet insulin resistance is not universal in PCOS patients (50) and even in insulinresistant PCOS patients, this defect may be tissuespecific $(51,52)$.

Therefore, in the hypothetical case that endothelial cells from PCOS patients are not more insulin resistant than that of non-hyperandrogenic women (53), the detrimental effect on endothelium exerted by oxidative stress, hypoadiponectinemia, and the proinflammatory milieu characteristics of PCOS women (10) may be counteracted by the anti-inflammatory and vasodilatatory actions of their frequently increased insulin levels, and by a putative vasodilatory effect of androgens $(54,55)$, preserving endothelial function until extreme obesity develops. Nevertheless, the presence of endothelial dysfunction in PCOS, especially when evaluated on the brachial artery by sonographic methods, is still a matter of intense debate (46), and, the small sample size of our study limits severely its power in detecting differences among PCOS women and non-hyperandrogenic controls (56).

The deleterious effect of smoking on endothelial function merits a specific consideration. In non-smoker PCOS patients, treatment with either Diane ${ }^{35}$ Diario of metformin improved endothelial function in parallel with a decrease in waist circumference, but smoking prevented the occurrence of this beneficial effect inducing a further deterioration of FMD in these women. Furthermore, the inclusion of smokers in our series may contribute to explain the differences with previous studies showing beneficial effects of metformin on endothelial function $(57,58)$, because in these earlier reports only non-smokers were included (57) or smoking was strongly discouraged (58). Finally, the intrinsic limitations of the ultrasonographic methods used here to evaluate endothelial function and the small sample size of our clinical trial - a hindrance further exaggerated by the subgrouping of the patients according to obesity and smoking - may have prevented us from finding differential effects of oral contraceptives and metformin on these indexes.

In summary, both oral contraceptives and metformin may exert deleterious effects on blood clotting tests of PCOS women, although the effects of metformin appear to be milder and potentially preventable by the co-administration of vitamin supplements. Because smoking potentiates some of these effects and deteriorates endothelial function, smoking cessation should be aggressively promoted in PCOS patients. Finally, most if not all the abnormalities in blood coagulation tests and indexes of endothelial function are influenced 
by abdominal adiposity, highlighting the contribution of adipose tissue dysfunction to the cardiovascular risk of PCOS.

\section{Declaration of interest}

The authors declare that there is no conflict of interest that could be perceived as prejudicing the impartiality of the research reported.

\section{Funding}

This study was supported by grants FIS PI050341 and PI080944 from Instituto de Salud Carlos III. CIBER de Diabetes y Enfermedades Metabólicas Asociadas (CIBERDEM) is also an initiative from Instituto de Salud Carlos III, Spanish Ministry of Science and Innovation.

\section{References}

1 Legro RS. Polycystic ovary syndrome and cardiovascular disease: a premature association? Endocrine Reviews 200324 302-312.

2 Apridonidze T, Essah PA, Iuorno MJ \& Nestler JE. Prevalence and characteristics of the metabolic syndrome in women with polycystic ovary syndrome. Journal of Clinical Endocrinology and Metabolism 200590 1929-1935.

3 Luque-Ramirez M, Alvarez-Blasco F, Botella-Carretero JI, Martinez-Bermejo E, Lasuncion MA \& Escobar-Morreale HF. Comparison of ethinyl-estradiol plus cyproterone acetate versus metformin effects on classic metabolic cardiovascular risk factors in women with the polycystic ovary syndrome. Journal of Clinical Endocrinology and Metabolism 200792 2453-2461.

4 Luque-Ramirez M, Mendieta-Azcona C, Alvarez-Blasco F \& Escobar-Morreale HF. Androgen excess is associated with the increased carotid intima-media thickness observed in young women with polycystic ovary syndrome. Human Reproduction 200722 3197-3203.

5 Talbott EO, Zborowski JV, Rager JR, Boudreaux MY, Edmundowicz DA \& Guzick DS. Evidence for an association between metabolic cardiovascular syndrome and coronary and aortic calcification among women with polycystic ovary syndrome. Journal of Clinical Endocrinology and Metabolism $2004 \mathbf{8 9}$ 5454-5461.

6 Yildiz BO, Haznedaroglu IC, Kirazli S \& Bayraktar M. Global fibrinolytic capacity is decreased in polycystic ovary syndrome, suggesting a prothrombotic state. Journal of Clinical Endocrinology and Metabolism 200287 3871-3875.

7 Paradisi G, Steinberg HO, Hempfling A, Cronin J, Hook G, Shepard MK \& Baron AD. Polycystic ovary syndrome is associated with endothelial dysfunction. Circulation 2001103 1410-1415.

8 Sakkinen PA, Wahl P, Cushman M, Lewis MR \& Tracy RP. Clustering of procoagulation, inflammation, and fibrinolysis variables with metabolic factors in insulin resistance syndrome. American Journal of Epidemiology 2000152 897-907.

9 Steinberg HO, Chaker H, Leaming R, Johnson A, Brechtel G \& Baron AD. Obesity/insulin resistance is associated with endothelial dysfunction. Journal of Clinical Investigation 199697 2601-2610.

10 Escobar-Morreale HF \& San Millan JL. Abdominal adiposity and the polycystic ovary syndrome. Trends in Endocrinology and Metabolism 200718 266-272.

11 Alvarez-Blasco F, Botella-Carretero JI, San Millan JL \& Escobar-Morreale HF. Prevalence and characteristics of the polycystic ovary syndrome in overweight and obese women. Archives of Internal Medicine $2006 \mathbf{1 6 6}$ 2081-2086.

12 Jick H, Jick SS, Gurewich V, Myers MW \& Vasilakis C. Risk of idiopathic cardiovascular death and nonfatal venous thromboembolism in women using oral contraceptives with differing progestagen components. Lancet 1995346 1589-1593.
13 Sidney S, Petitti DB, Soff GA, Cundiff DL, Tolan KK \& Quesenberry CP Jr. Venous thromboembolic disease in users of low-estrogen combined estrogen-progestin oral contraceptives. Contraception $2004703-10$.

14 Pomp ER, Rosendaal FR \& Doggen CJ. Smoking increases the risk of venous thrombosis and acts synergistically with oral contraceptive use. American Journal of Hematology $2008 \mathbf{8 3} 97-102$.

15 Luque-Ramirez M, Alvarez-Blasco F, Botella-Carretero JI, Sanchon R, San Millan JL \& Escobar-Morreale HF. The increased body iron stores of obese women with polycystic ovary syndrome are a consequence of insulin resistance and hyperinsulinism, and do not result from reduced menstrual losses. Diabetes Care 2007 $302309-2313$.

16 Luque-Ramirez M, Mendieta-Azcona C, Alvarez-Blasco F \& Escobar-Morreale HF. Effects of metformin versus ethinyl-estradiol plus cyproterone acetate on ambulatory blood pressure monitoring and carotid intima media thickness in women with the polycystic ovary syndrome. Fertility and Sterility, 2008. In Press, DOI: 10.1016/j.fertnstert.2008.03.082.

17 Luque-Ramirez M, Alvarez-Blasco F, Uriol Rivera MG \& EscobarMorreale HF. Serum uric acid concentration as non-classic cardiovascular risk factor in women with polycystic ovary syndrome: effect of treatment with ethinyl-estradiol plus cyproterone acetate versus metformin. Human Reproduction 200823 1594-1601.

18 Luque-Ramirez M, Alvarez-Blasco F \& Escobar-Morreale HF. Antiandrogenic contraceptives increase serum adiponectin in obese polycystic ovary syndrome patients. Obesity 200917 3-9.

19 Zawadzki JK \& Dunaif A. Diagnostic criteria for polycystic ovary syndrome: towards a rational approach. In Polycystic Ovary Syndrome, pp 377-387. Eds A Dunaif, JR Givens, FP Haseltine \& GR Merriam, Boston: Blackwell Scientific Publications, 1992.

20 The Rotterdam ESHRE/ASRM-sponsored PCOS consensus workshop group. Revised 2003 consensus on diagnostic criteria and long-term health risks related to polycystic ovary syndrome (PCOS). Human Reproduction 200419 41-47.

21 Azziz R, Carmina E, Dewailly D, Diamanti-Kandarakis E, EscobarMorreale HF, Futterweit W, Janssen OE, Legro RS, Norman RJ, Taylor AE \& Witchel SF. Position statement: criteria for defining polycystic ovary syndrome as a predominantly hyperandrogenic syndrome: an androgen excess society guideline. Journal of Clinical Endocrinology and Metabolism 200691 4237-4245.

22 Escobar-Morreale HF, Sanchon R \& San Millan JL. A prospective study of the prevalence of nonclassical congenital adrenal hyperplasia among women presenting with hyperandrogenic symptoms and signs. Journal of Clinical Endocrinology and Metabolism 200893 527-533.

23 Luque-Ramirez M, Alvarez-Blasco F, Mendieta-Azcona C, BotellaCarretero JI \& Escobar-Morreale HF. Obesity is the major determinant of the abnormalities in blood pressure found in young women with the polycystic ovary syndrome. Journal of Clinical Endocrinology and Metabolism 200792 2141-2148.

24 Clauss A. Gerinnungsphysiologische schnellmethode zur bestimmung des fibrinogens. Acta Haematologica 195717 237-246.

25 Celermajer DS, Sorensen KE, Gooch VM, Spiegelhalter DJ, Miller OI, Sullivan ID, Lloyd JK \& Deanfield JE. Non-invasive detection of endothelial dysfunction in children and adults at risk of atherosclerosis. Lancet 1992340 1111-1115.

26 Corretti MC, Anderson TJ, Benjamin EJ, Celermajer D, Charbonneau F, Creager MA, Deanfield J, Drexler H, GerhardHerman M, Herrington D, Vallance P, Vita J \& Vogel R. Guidelines for the ultrasound assessment of endothelial-dependent flowmediated vasodilation of the brachial artery: a report of the International Brachial Artery Reactivity Task Force. Journal of the American College of Cardiology 200239 257-265.

27 Fryer RH, Wilson BD, Gubler DB, Fitzgerald LA \& Rodgers GM. Homocysteine, a risk factor for premature vascular disease and thrombosis, induces tissue factor activity in endothelial cells. Arteriosclerosis and Thrombosis 199313 1327-1333.

28 Barrett-Connor E \& Khaw KT. Cigarette smoking and increased central adiposity. Annals of Internal Medicine 1989111 783-787. 
29 Canoy D, Wareham N, Luben R, Welch A, Bingham S, Day N \& Khaw KT. Cigarette smoking and fat distribution in 21828 British men and women: a population-based study. Obesity Research 2005 13 1466-1475.

30 Akbartabartoori M, Lean ME \& Hankey CR. Relationships between cigarette smoking, body size and body shape. International Journal of Obesity 200529 236-243.

31 De Pergola G, De Mitrio V, Giorgino F, Sciaraffia M, Minenna A, Di Bari L, Pannacciulli N \& Giorgino R. Increase in both prothrombotic and anti-thrombotic factors in obese premenopausal women: relationship with body fat distribution. International Journal of Obesity and Related Metabolic Disorders 199721 527-535.

32 Mertens I \& Van Gaal LF. Obesity, haemostasis and the fibrinolytic system. Obesity Reviews 20023 85-101.

33 Petitti DB. Oral contraceptives and hypercoagulation. Clinical Advances in Hematology and Oncology 20064 813-815.

34 Franks S, Layton A \& Glasier A. Cyproterone acetate/ethinyl estradiol for acne and hirsutism: time to revise prescribing policy. Human Reproduction 200823 231-232.

35 Seaman HE, de Vries CS \& Farmer RD. The risk of venous thromboembolism in women prescribed cyproterone acetate in combination with ethinyl estradiol: a nested cohort analysis and case-control study. Human Reproduction $200318522-526$.

36 Diamanti-Kandarakis E, Baillargeon J-P, Iuorno MJ, Jakubowicz DJ \& Nestler JE. A modern medical quandary: polycystic ovary syndrome, insulin resistance, and oral contraceptive pills. Journal of Clinical Endocrinology and Metabolism $2003 \mathbf{8 8}$ 1927-1932.

37 Morin-Papunen L, Vauhkonen I, Koivunen R, Ruokonen A, Martikainen H \& Tapanainen JS. Metformin versus ethinyl estradiol-cyproterone acetate in the treatment of nonobese women with polycystic ovary syndrome: a randomized study. Journal of Clinical Endocrinology and Metabolism $2003 \mathbf{8 8}$ 148-156.

38 Nader S \& Diamanti-Kandarakis E. Polycystic ovary syndrome, oral contraceptives and metabolic issues: new perspectives and a unifying hypothesis. Human Reproduction 200722 317-322.

39 Wulffele MG, Kooy A, Lehert P, Bets D, Ogterop JC, Borger van der Burg B, Donker AJ \& Stehouwer CD. Effects of short-term treatment with metformin on serum concentrations of homocysteine, folate and vitamin B12 in type 2 diabetes mellitus: a randomized, placebo-controlled trial. Journal of Internal Medicine 2003254 455-463.

40 Vrbikova J, Bicikova M, Tallova J, Hill M \& Starka L. Homocysteine and steroids levels in metformin treated women with polycystic ovary syndrome. Experimental and Clinical Endocrinology and Diabetes 2002110 74-76.

41 Kilicdag EB, Bagis T, Zeyneloglu HB, Tarim E, Aslan E, Haydardedeoglu B \& Erkanli S. Homocysteine levels in women with polycystic ovary syndrome treated with metformin versus rosiglitazone: a randomized study. Human Reproduction 200520 894-899.

42 Carlsen SM, Kjotrod S, Vanky E \& Romundstad P. Homocysteine levels are unaffected by metformin treatment in both nonpregnant and pregnant women with polycystic ovary syndrome. Acta Obstetricia et Gynecologica Scandinavica 200786 145-150.

43 Pinhas-Hamiel O, Doron-Panush N, Reichman B, NitzanKaluski D, Shalitin S \& Geva-Lerner L. Obese children and adolescents: a risk group for low vitamin B12 concentration. Archives of Pediatrics E Adolescent Medicine $2006160933-936$.
44 Bauman WA, Shaw S, Jayatilleke E, Spungen AM \& Herbert V. Increased intake of calcium reverses vitamin B12 malabsorption induced by metformin. Diabetes care 200023 1227-1231.

45 Zakai NA, Ohira T, White R, Folsom AR \& Cushman M. Activated partial thromboplastin time and risk of future venous thromboembolism. American Journal of Medicine 2008121 231-238.

46 Beckman JA, Goldfine AB, Dunaif A, Gerhard-Herman M \& Creager MA. Endothelial function varies according to insulin resistance disease type. Diabetes Care 200730 1226-1232.

47 Dunaif A, Wu X, Lee A \& Diamanti-Kandarakis E. Defects in insulin receptor signaling in vivo in the polycystic ovary syndrome (PCOS). American Journal of Physiology-Endocrinology and Metabolism 2001281 E392-E399.

48 Carmassi F, De Negri F, Fioriti R, De Giorgi A, Giannarelli C, Fruzzetti F, Pedrinelli R, Dell'Omo G \& Bersi C. Insulin resistance causes impaired vasodilation and hypofibrinolysis in young women with polycystic ovary syndrome. Thrombosis Research $2005116207-214$.

49 Muniyappa R, Montagnani M, Koh KK \& Quon MJ. Cardiovascular actions of insulin. Endocrine Reviews 200728 463-491.

50 DeUgarte CM, Bartolucci AA \& Azziz R. Prevalence of insulin resistance in the polycystic ovary syndrome using the homeostasis model assessment. Fertility and Sterility 200583 1454-1460.

51 Baillargeon JP \& Nestler JE. Commentary: polycystic ovary syndrome: a syndrome of ovarian hypersensitivity to insulin? Journal of Clinical Endocrinology and Metabolism 200691 22-24.

52 Corbould A \& Dunaif A. The adipose cell lineage is not intrinsically insulin resistant in polycystic ovary syndrome. Metabolism: Clinical and Experimental $2007 \mathbf{5 6} 716-722$.

53 Ketel IJ, Stehouwer CD, Serne EH, Korsen TJ, Hompes PG, Smulders YM, de Jongh RT, Homburg R \& Lambalk CB. Obese but not normal-weight women with polycystic ovary syndrome are characterized by metabolic and microvascular insulin resistance. Journal of Clinical Endocrinology and Metabolism 2008 93 3365-3372.

$54 \mathrm{Wu}$ FC \& von Eckardstein A. Androgens and coronary artery disease. Endocrine Reviews 200324 183-217.

55 Littleton-Kearney M \& Hurn PD. Testosterone as a modulator of vascular behavior. Biological Research for Nursing 20045 276-285.

56 Liang YL, Teede H, Kotsopoulos D, Shiel L, Cameron JD, Dart AM \& McGrath BP. Non-invasive measurements of arterial structure and function: repeatability, interrelationships and trial sample size. Clinical Science 199895 669-679.

57 Orio F Jr, Palomba S, Cascella T, De Simone B, Manguso F, Savastano S, Russo T, Tolino A, Zullo F, Lombardi G, Azziz R \& Colao A. Improvement in endothelial structure and function after metformin treatment in young normal-weight women with polycystic ovary syndrome: results of a 6-month study. Journal of Clinical Endocrinology and Metabolism 200590 6072-6076.

58 Jensterle M, Sebestjen M, Janez A, Prezelj J, Kocjan T, Keber I \& Pfeifer M. Improvement of endothelial function with metformin and rosiglitazone treatment in women with polycystic ovary syndrome. European Journal of Endocrinology 2008 159 399-406.

Received 27 December 2008

Accepted 3 January 2009 